\title{
Clinicopathological and prognostic significance of pretreatment thrombocytosis in patients with endometrial cancer: a meta-analysis
}

This article was published in the following Dove Press journal: Cancer Management and Research

\author{
Yi-Yang Bai ${ }^{1, *}$ \\ Lan $\mathrm{Du}^{2, *}$ \\ Li Jing' \\ Tao Tian' \\ Xuan Liang' \\ Min Jiao' \\ Ke-Jun Nan' \\ Hui Guol \\ Zhi-Ping Ruan' \\ 'Department of Medical Oncology, The \\ First Affiliated Hospital, College of \\ Medicine of Xi'an Jiaotong University, \\ Xi'an, Shaanxi, People's Republic of \\ China; ${ }^{2}$ Department of Obstetrics and \\ Gynecology, Xi'an Angel Women's and \\ Children's Hospital, Xian, Shaanxi, \\ People's Republic of China \\ *These authors contributed equally to \\ this work
}

\begin{abstract}
Background: The prognostic and clinicopathological role of pretreatment thrombocytosis in cancer has been widely studied, but conclusions in endometrial cancer (EnCa) remain controversial. Therefore, we conducted a meta-analysis to assess the pathologic and prognostic impacts of pretreatment thrombocytosis in patients with EnCa.
\end{abstract}

Methods: We searched PubMed, Embase, SpringerLink, ScienceDirect and China National Knowledge Infrastructure databases. Pooled HR or OR with their 95\% CIs were applied to assess the association of pretreatment thrombocytosis with survival outcomes and clinical parameters of EnCa patients.

Results: In total, 10 studies containing 2,995 cases of EnCa met the criteria. The results suggested that pretreatment thrombocytosis was significantly associated with high International Federation of Gynecology and Obstetrics (FIGO) stage (pooled OR 3.45, 95\% CI 1.68-7.08, $P=0.001$ ), poor tumor differentiation (pooled OR $2.00,95 \% \mathrm{CI}$ 1.22-3.29, $P=0.006$ ), lymph-vascular space invasion (pooled OR 2.04, 95\% CI 1.35-3.07, $P=0.001$ ); myometrial invasion (pooled OR 2.14, 95\% CI 1.39-3.32, $P=0.001$ ); cervical involvement (pooled OR 2.54, 95\% CI 1.56-4.15, $P=0.000$ ) and lymph node metastasis (OR $3.15,95 \%$ CI 1.71-5.80, $P=0.001)$. No significant difference existed between pretreatment thrombocytosis and overall survival $(P=0.012)$, cancer/disease-specific survival $(P=0.07)$ or disease-free survival $(P=0.25)$.

Conclusion: pretreatment thrombocytosis was associated with advanced clinicopathological features in patients with $\mathrm{EnCa}$, which may serve as a potential therapeutic target for EnCa. Keywords: thrombocytosis, endometrial cancer, prognosis, meta-analysis

\section{Introduction}

Endometrial cancer $(\mathrm{EnCa})$ is the most common gynecological malignancy with a rising incidence in developed countries. ${ }^{1}$ Most patients $(80 \%)$ are commonly diagnosed at the early stage and can be surgically cured. However, patients with metastatic or recurrent disease portend a poor prognosis, with a 5-year survival rate of 5.3-20.1\%, as there are limited treatment options. ${ }^{2,3}$ Prognostic assessment is essential for treatment decision-making. Clinically, the prognosis of EnCa is heterogeneous due to variations in tumor biology. ${ }^{4}$ Some patients with the same stage or pathologic prognostic factors have various clinical courses and survival outcomes. ${ }^{5}$ Therefore, additional prognostic markers are needed to guide therapeutic options and surveillance strategies.

Recently, studies have shown that tumor-platelet interactions is associated with tumorigenesis. Specifically, elevated platelet count or thrombocytosis has been
Correspondence: Hui Guo; Zhi-Pin Ruan Department of Medical Oncology, The First Affiliated Hospital, College of Medicine of Xi'an Jiaotong University, No. 277 Yanta West Road, Xi'an, Shaanxi 7I006I, People's Republic of China Email guohuihappy97@163.com; zopor@I63.com 
identified as a marker of cancer prognosis and may reflect tumor burden. Todenhöfer $\mathrm{T}$ et al reported thrombocytosis could be used as a prognostic parameter and constructed a more accurate prognostic model according to pretreatment platelet count and established pathological factors. ${ }^{6}$ Several studies have suggested that preoperative thrombocytosis associated with poor survival in gynecological malignancies, such as ovarian and cervicalcancer. ${ }^{7,8}$ So the relationship between thrombocytosis and prognosis of EnCa is worth further study Pretreatment thrombocytosis has been reported by most researches to be correlated with poor prognosis of EnCa. However, conflicting results exist and a consensus cannot be achieved. Takahashi et $\mathrm{al}^{9}$ suggested that pretreatment thrombocytosis significantly predicted unfavorable survival. Heng and Benjapibal ${ }^{10}$ reported that thrombocytosis was not a prognostic factor of EnCa in the multivariate analysis. Against this background, we performed a comprehensive and quantitative evaluation of the literature about the relationships between pretreatment thrombocytosis and survival and clinicopathological features in EnCa.

\section{Methods}

The study was performed according to the PRISMA statement. ${ }^{11}$

\section{Search strategy}

Our search was restricted to the English and Chinese using databases from PubMed, Embase, SpringerLink, ScienceDirect and China National Knowledge Infrastructure up to July 15, 2018. Both medical subject heading (Mesh) terms and free-text terms included $\mathrm{EnCa}$, thrombocytosis and prognosis. The full search strategy is available in the Supplementary materials. The bibliographies of the retrieved articles were also manually scrutinized for potential related articles.

\section{Selection criteria}

The criteria for inclusion were as follows: 1) prospective or retrospective studies analyzed the relationship between thrombocytosis and clinicopathological factors or prognosis of EnCa; 2) the cutoff values of thrombocytosis were reported; and 3) the most complete study was included if multiple studies described the same cohorts studies were excluded based on the following criteria: (1) studies for the lack of information for further analysis; (2) laboratory articles; and (3) non-research articles (abstracts, letters, comments or reviews).

\section{Definitions and data extraction}

Overall survival (OS) was defined as the interval between the initial surgical procedure and the death or the last follow-up. Cancer/disease-specific survival (DSS) was defined as the time from initial diagnosis to date of death attributed to EnCa. Disease-free survival (DFS) was measured from the day of surgery to the time of local/distant disease progression or the date of last follow-up. The following data were collected: (1) publication details: first author's surname, publication year, country of study, age and sample size; (2) study design: study type (prospective/ retrospective study), cutoff points; (3) patients characteristics (patients number and age); and (4) follow-up data (median/mean follow-up duration, survival analysis).

\section{Quality assessment}

The Newcastle-Ottawa Scale (NOS) criterion ${ }^{12}$ was used to evaluate the quality of the included studies (Table S1). The scores were judged based on the three aspects of NOS, namely, selection, comparability and outcomes. Studies achieving scores $\geq 6$ were defined as high quality (Table S2).

\section{Statistical analyses}

For the quantitative aggregation of results, pooled OR with 95\% CI were used to evaluate the association of thrombocytosis with clinicopathological features of patients. The HR with 95\% CI were used to analyze postoperative OS, cancer/ DSS, or DFS, which was directly retrieved from each of included article. Pooled OR and HR were calculated using random-effect model. Heterogeneity was performed by using chi-square-based Q-test. The $I^{2}$ value indicated the degree of heterogeneity. A $P$-value $<0.10$ or $I^{2}>50 \%$ indicated significant heterogeneity. All statistical analyses were carried out by Review Manager 5.3 (Cochrane Collaboration, London, UK).

\section{Results}

\section{Characteristics of included studies}

The detail search process is shown in Figure 1. The initial search retrieved a total of 339 published studies. Out of which, 146 studies were excluded due to duplicate records. After screening titles and abstracts, we removed 162 publications including 148 irrelevant studies and 14 reports without clinical specimens. Further evaluating, finally, we included 10 studies in the final meta-analysis. ${ }^{9}, 10,13-20$ Sample sizes ranged from 68 to 1166 patients. All included studies including 2995 patients were counted for the incidence of thrombocytosis ranged from $2.3 \%$ to 


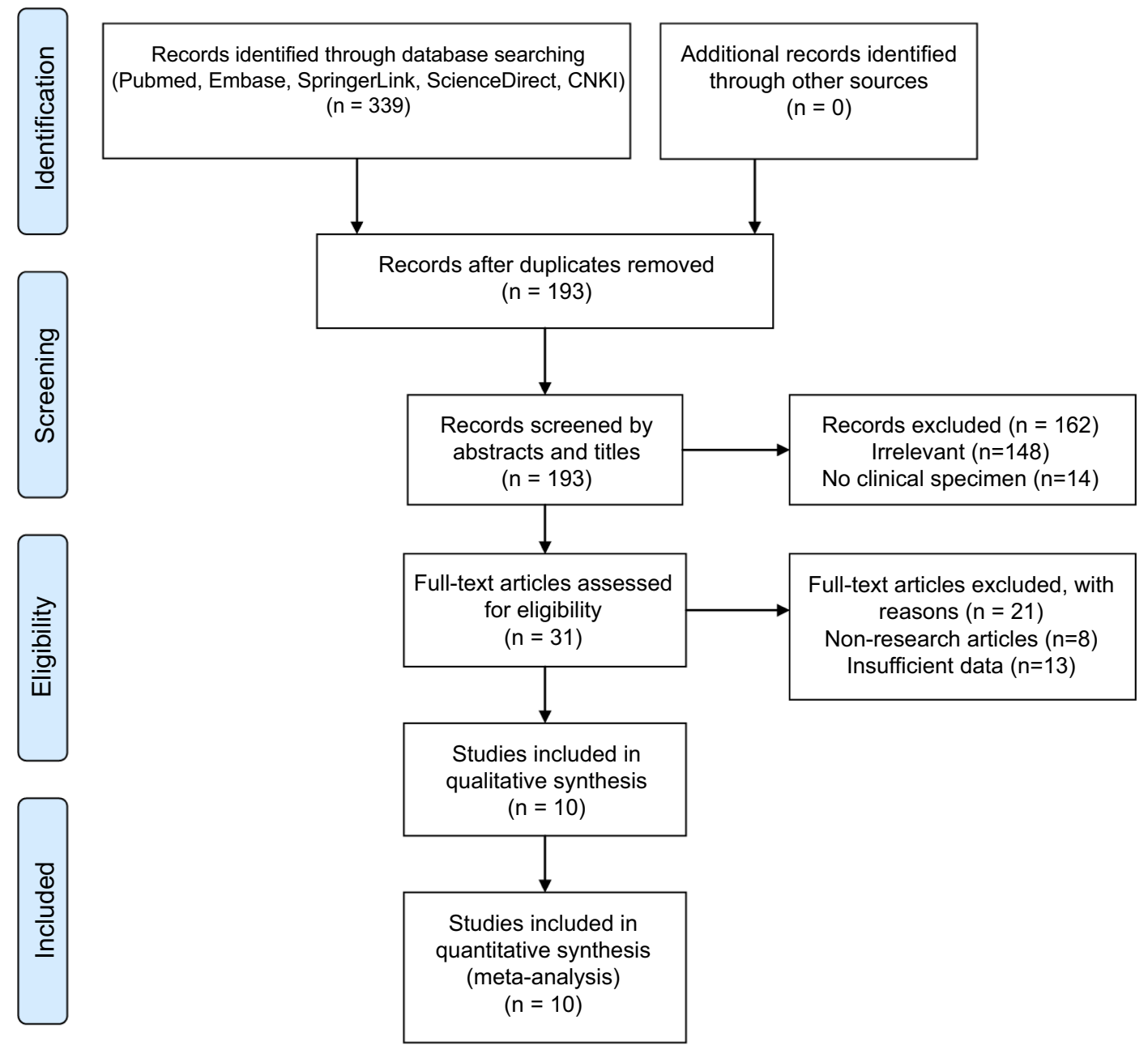

Figure I Flow diagram of the search strategy.

$18.2 \%$. The study by Njølstad et $\mathrm{al}^{15}$ was a prospective study. The remaining studies were retrospective. All the included studies did not report the methods to measure pretreatment thrombocytosis in detail. Three studies ${ }^{10,16,19}$ stated that platelet count in each case was obtained within 14 days before surgery. The detailed characteristics of eligible studies are described in Table 1.

\section{Correlation of preoperative thrombocytosis and clinicopathological feature}

Four studies ${ }^{9,10,13,17}$ involving 1133 patients reported the association of FIGO stage with preoperative thrombocytosis. The pooled OR revealed that patients with preoperative thrombocytosis were more likely to have high FIGO stage categories (OR 3.45, 95\% CI 1.68-7.08, $P=0.001$; Figure 2A). Five

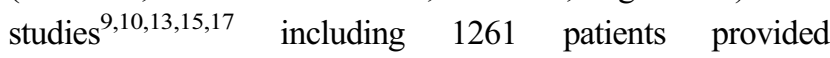

information regarding histological grade. The pooled analysis showed that thrombocytosis was linked to high histological grading (pooled OR 2.00, 95\% CI 1.22-3.29, $P=0.006$; Figure 2B). Four studies ${ }^{9,10,15,17}$ described preoperative thrombocytosis according to histologic subtype and lymph-vascular space invasion (LVSI). The pooled data showed thrombocytosis correlated with LVSI (pooled OR 2.04, 95\% CI 1.35-3.07, $P=0.001$; Figure $2 \mathrm{C}$ ), but there were no significant associations of histologic subtype (pooled OR $0.79,95 \%$ CI $0.39-1.60, P=0.52$; Figure $3 \mathrm{~A}$ ). The combined results showed that thrombocytosis was significantly associated with cervical involvement (pooled OR 2.54, 95\% CI 1.56-4.15, $P=0.000$; Figure 3B) and myometrial invasion (pooled OR 2.14, 95\% CI 1.39-3.32, $P=0.001$; Figure $3 \mathrm{C}$ ) and in three studies. ${ }^{9,10,15}$ The pooled OR revealed that preoperative thrombocytosis was associated with lymph node metastasis (OR 3.15, 95\% CI $1.71-5.80, P=0.001$ Figure 3D) by analyzing two studies. ${ }^{9,10}$ 


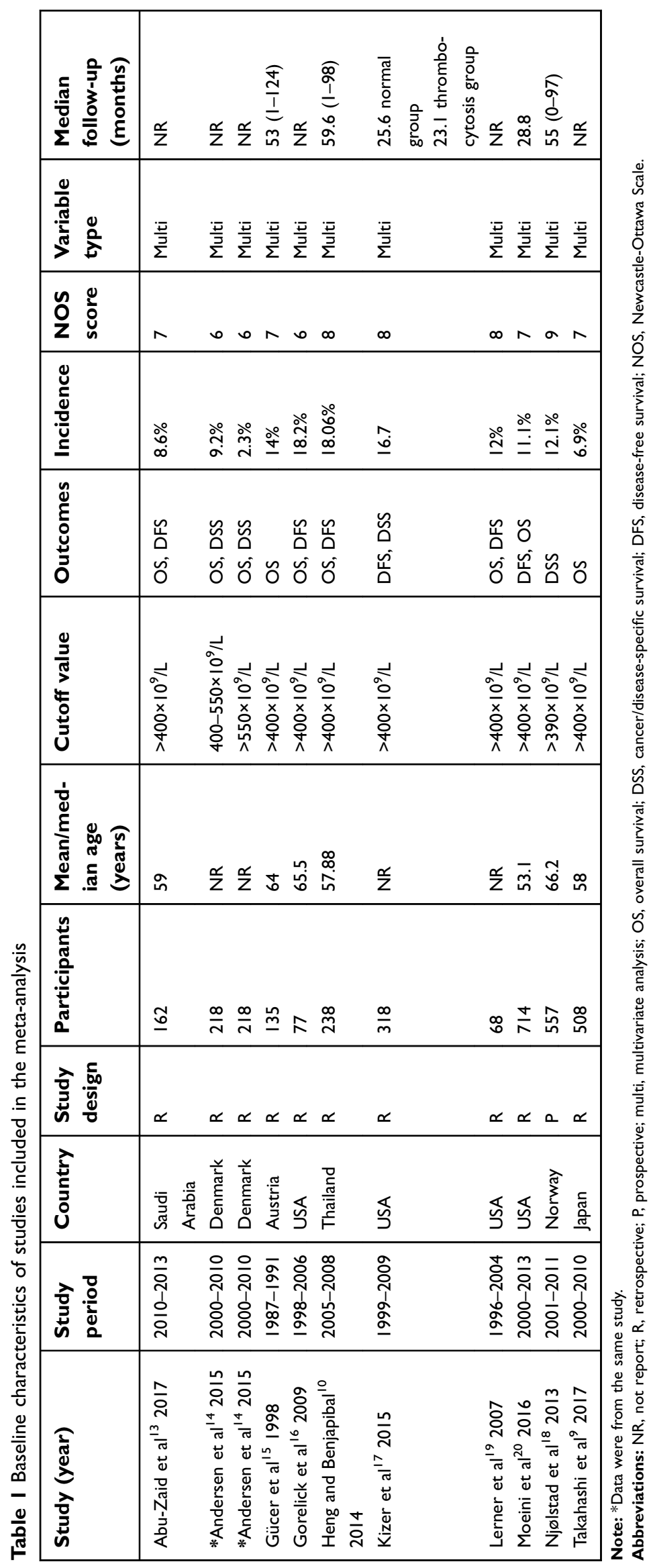


A

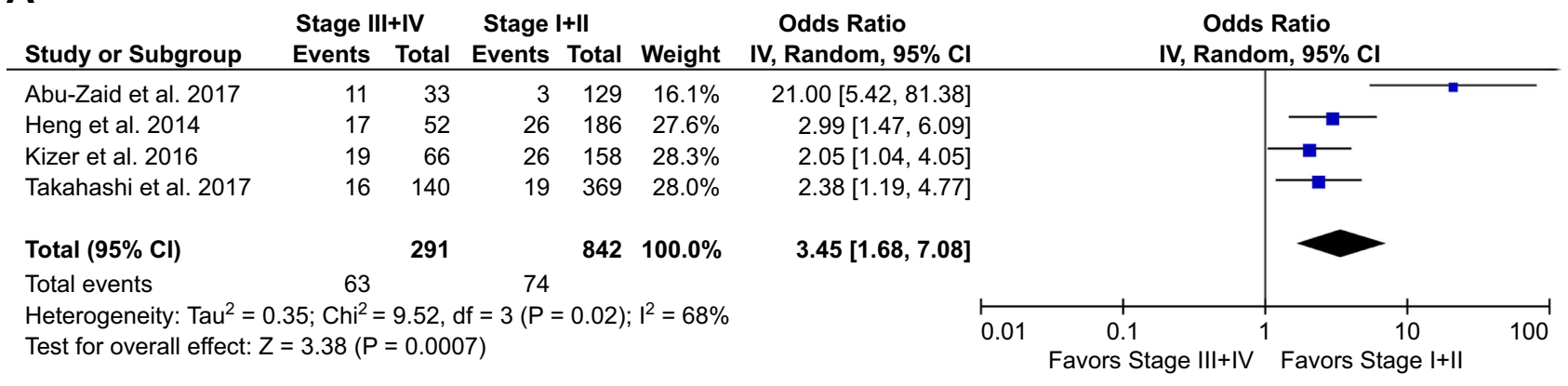

B

\begin{tabular}{|c|c|c|c|c|c|c|c|c|c|c|}
\hline \multirow{2}{*}{$\begin{array}{l}\text { Study or Subgroup } \\
\text { Abu-Zaid et al. } 2017\end{array}$} & \multicolumn{2}{|c|}{ Grade II+III } & \multicolumn{2}{|c|}{ Grade I } & Weight & $\begin{array}{c}\text { Odds Ratio } \\
\text { IV, Random, } 95 \% \mathrm{CI}\end{array}$ & \multicolumn{3}{|c|}{$\begin{array}{c}\text { Odds Ratio } \\
\text { IV, Random, } 95 \% \mathrm{CI}\end{array}$} & \\
\hline & 12 & 86 & 2 & 76 & $9.1 \%$ & $6.00[1.30,27.74]$ & & & 7 & \\
\hline Gücer F et al. 1998 & 14 & 59 & 5 & 76 & $15.9 \%$ & $4.42[1.49,13.10]$ & & & & \\
\hline Heng et al. 2014 & 18 & 87 & 16 & 109 & $26.7 \%$ & $1.52[0.72,3.18]$ & & & & \\
\hline Kizer et al. 2016 & 41 & 237 & 7 & 50 & $22.0 \%$ & $1.28[0.54,3.06]$ & & & & \\
\hline Takahashi et al. 2017 & 21 & 263 & 11 & 218 & $26.3 \%$ & $1.63[0.77,3.47]$ & & & & \\
\hline Total $(95 \% \mathrm{Cl})$ & & 732 & & 529 & $100.0 \%$ & $2.00[1.22,3.29]$ & & & & \\
\hline Total events & 106 & & 41 & & & & & & & \\
\hline $\begin{array}{l}\text { Heterogeneity: } \operatorname{Tau}^{2}=0 \\
\text { Test for overall effect: } Z\end{array}$ & $\begin{array}{l}10 ; \mathrm{Chi}^{2}= \\
=2.74(\mathrm{P}\end{array}$ & $\begin{array}{l}=5.77, \mathrm{~d} \\
=0.006)\end{array}$ & df $=4(P=$ & $=0.22)$ & $I^{2}=31 \%$ & & 0.01 & $\begin{array}{c}0.1 \\
\text { Favors Grade } I I+I I I\end{array}$ & $\begin{array}{lc}10 & 10 \\
& \text { Favors Grade I }\end{array}$ & 100 \\
\hline & LVSI & & LVSII & & & Odds Ratio & & Odds & S Ratio & \\
\hline Study or Subgroup & Events & Total & Events & Total & Weight & IV, Random, $95 \% \mathrm{CI}$ & & IV, Rand & om, $95 \% \mathrm{Cl}$ & \\
\hline Gücer F et al. 1998 & 8 & 28 & 11 & 107 & $15.9 \%$ & $3.49[1.25,9.78]$ & & & 7 & \\
\hline Heng et al. 2014 & 8 & 39 & 33 & 188 & $22.7 \%$ & $1.21[0.51,2.87]$ & & & & \\
\hline Kizer et al. 2016 & 40 & 221 & 8 & 90 & $26.3 \%$ & $2.27[1.02,5.05]$ & & & & \\
\hline Takahashi et al. 2017 & 20 & 206 & 15 & 302 & $35.1 \%$ & $2.06[1.03,4.12]$ & & & & \\
\hline Total $(95 \% \mathrm{Cl})$ & & 494 & & 687 & $100.0 \%$ & $2.04[1.35,3.07]$ & & & & \\
\hline Total events & 76 & & 67 & & & & & & & \\
\hline
\end{tabular}

Figure 2 Association of pretreatment thrombocytosis with clinicopathological parameters. (A) FIGO stage; (B) tumor differentiation; and (C) lymph-vascular space invasion.

\section{Impact of preoperative thrombocytosis on survival}

As seen in Figure 4, six ${ }^{9,10,13,16,19,20}$ of the included studies showed was preoperative thrombocytosis was not associated with OS in EnCa patients (pooled $\mathrm{HR}=1.65,95 \%$ CI: $0.88-3.11, P=0.012, I^{2}=82 \%$, Figure $4 \mathrm{~A}$ ). The synthesized data from four studies ${ }^{10,13,17,20}$ suggested that thrombocytosis did not correlate with poor DFS (pooled HR $=1.66,95 \%$ CI: $0.96-2.89, P=0.07, I^{2}=59 \%$, Figure 4B). There was no association between preoperative thrombocytosis and DSS (pooled HR $=1.37,95 \%$ CI: $0.80-2.36$, $P=0.25, I^{2}=40 \%$, Figure 4C). Particularly, Andersen et $\mathrm{al}^{14}$ divided the preoperative platelet count into two categories of thrombocytosis (mild, platelet count $=400-550 \times 10^{9} / \mathrm{L}$; severe, platelet count $>550 \times 109 / \mathrm{L}$ ). The study reported that mild and severe preoperative thrombocytosis was all not associated with cancer-specific mortality.

\section{Subgroup and sensitivity analysis}

Stratified analysis was conducted to assess the prognostic value of thrombocytosis on OS and DFS according to geographic region, sample size, and NOS score. As shown in Table 2, stratified analysis did not alter the prognostic role of preoperative thrombocytosis on OS, except for the subgroup small sample size (pooled HR $=1.88,95 \%$ CI: $1.26-2.80$, $P=0.002, I^{2}=0 \%$ ). However, the EnCa patients with preoperative thrombocytosis showed a significant worse DFS in subgroups of Asian patients (pooled HR $=2.21,95 \%$ CI: 1.17-4.21, $P=0.02, \quad I^{2}=0 \%$ ), NOS scores $>7$ (pooled $\mathrm{HR}=2.16,95 \%$ CI: $1.34-3.56, P=0.002, I^{2}=0 \%$ ). We further performed a sensitivity analysis to gauge the stability of the results. The pooled effects of OS was significantly altered when the study by Heng and Benjapibal ${ }^{10}$ was omitted (pooled $\mathrm{HR}=2.04,95 \% \mathrm{CI}=1.11-3.73, P=0.02$, Table 3 ). When the study by Moeini et $\mathrm{al}^{20}$ was removed, the pooled results for 
A

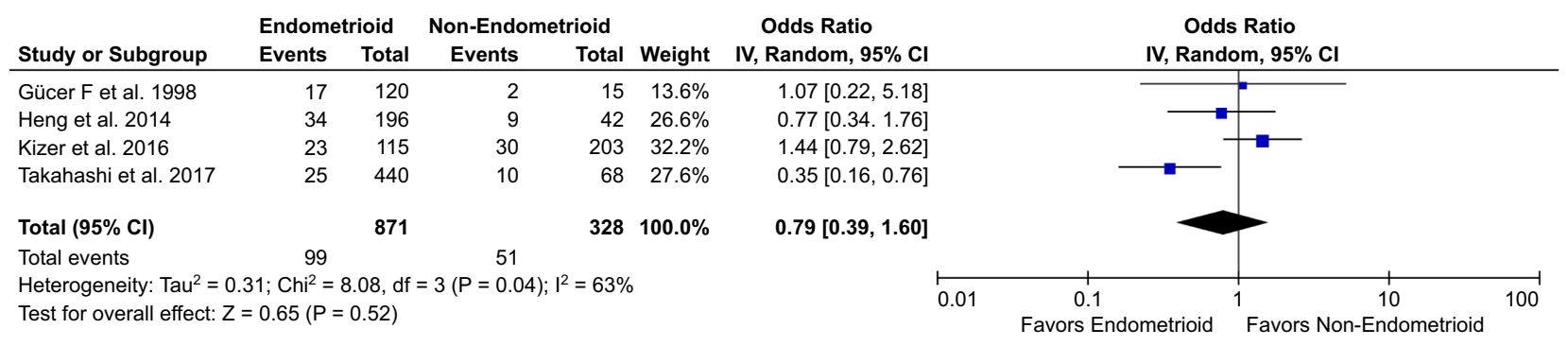

B

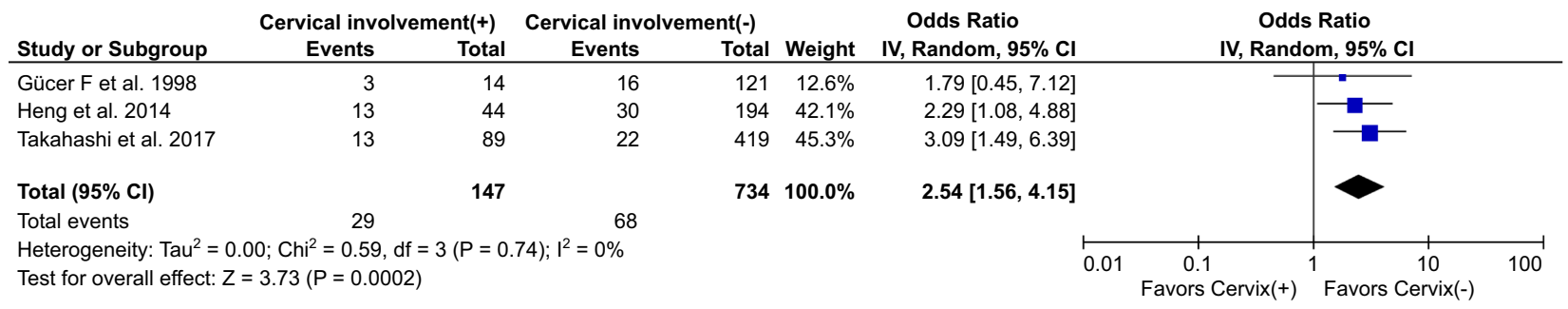

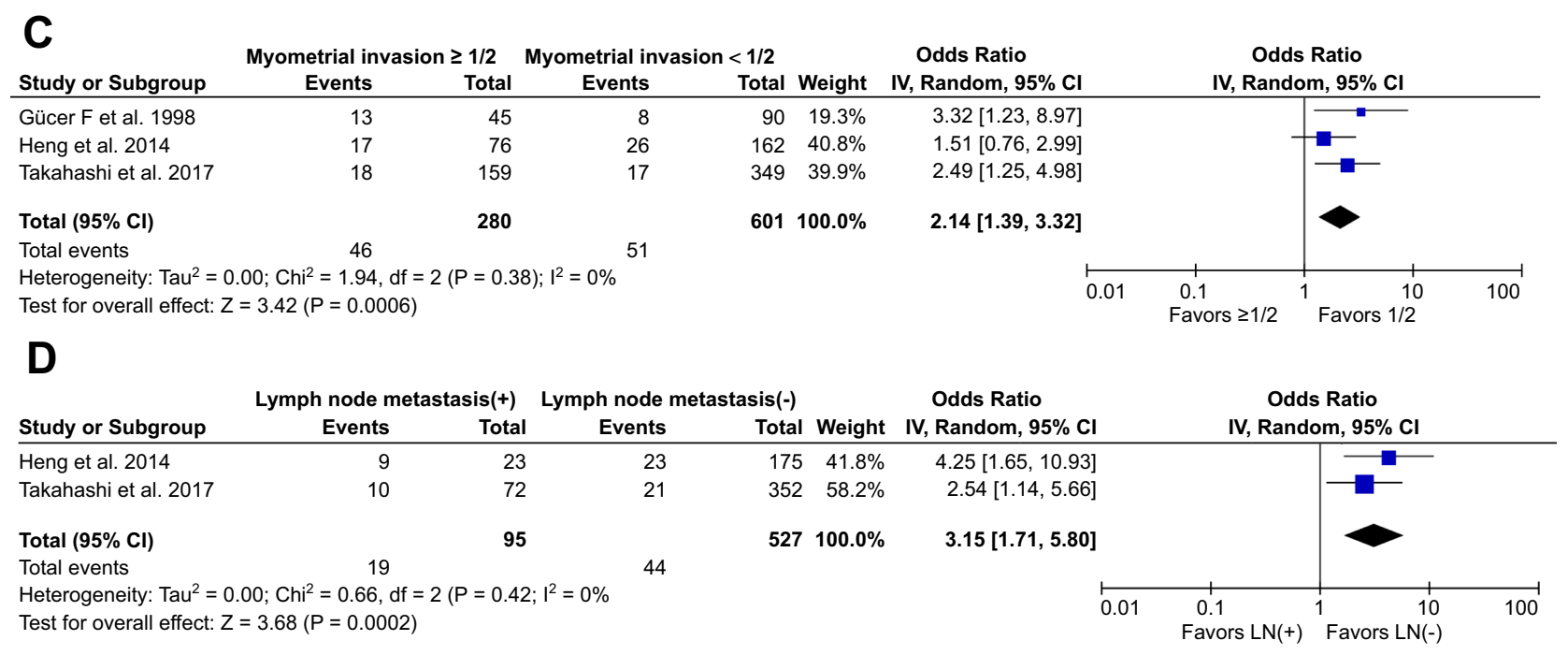

Figure 3 Association of pretreatment thrombocytosis with clinicopathological factors. (A) histologic subtype; (B) cervical involvement; (C) myometrial invasion; and (D) lymph node metastasis.

DFS were significantly altered (pooled $\mathrm{HR}=2.23,95 \%$ $\mathrm{CI}=1.45-3.42, P=0.000$, Table 3 ). We did not evaluate publication bias since the number of included studies was limited.

\section{Discussion}

Thrombocytosis in cancer patients is a common finding and preoperative thrombocytosis has a strong connection to cancer outcomes. ${ }^{21,22}$ However, conflicting studies exist regarding the prognostic effects of thrombocytosis on EnCa patients. ${ }^{9,10}$ So we performed the meta-analysis to reassess the association of preoperative thrombocytosis with clinicopathological factors and prognosis of EnCa. In the current study, the pooled effects indicated that preoperative thrombocytosis was positively correlated with high FIGO stage, high histological grading, LVSI, myometrial invasion, cervical involvement and lymph node metastasis in EnCa patients. Nonetheless, preoperative thrombocytosis was not associated with poor OS, DFS, and DSS (all included studies were used multivariate analysis). According to NOS quality assessment, all included studies were high quality and the scores of ranged from 6 to 9 (median 7). So we defined the cutoff value of NOS quality as 7 when performing stratification analysis. EnCa patients with preoperative thrombocytosis showed a reduced DFS in subgroups of Asian patients and studies with NOS scores larger than 7 . 


\begin{tabular}{|c|c|c|c|c|c|c|c|}
\hline $\begin{array}{l}\text { A } \\
\text { Study or Subgroup }\end{array}$ & log[Hazard Ratio] & E Weight & $\begin{array}{c}\text { Hazard Ratio } \\
\text { IV, Random, } 95 \% \mathrm{CI}\end{array}$ & & $\begin{array}{r}\text { Hazar } \\
\text { IV, Rando }\end{array}$ & $\begin{array}{l}\text { rd Ratio } \\
\text { om, } 95 \% \mathrm{Cl}\end{array}$ & \\
\hline Abu-Zaid et al. 2017 & 0.580 .4987 & $14.1 \%$ & $1.79[0.67,4.75]$ & & & $t=$ & \\
\hline Gorelick et al. 2009 & 0.53880 .2476 & $18.9 \%$ & $1.71[1.05,2.78]$ & & & & \\
\hline Heng et al. 2014 & -0.43080 .2477 & $18.9 \%$ & $0.65[0.40,1.06]$ & & & & \\
\hline Lerner et al. 2006 & 1.11510 .5392 & $2 \quad 13.4 \%$ & $3.05[1.06,8.78]$ & & & & \\
\hline Moeini et al. 2016 & $-0.1165 \quad 0.315$ & $5 \quad 17.7 \%$ & $0.89[0.48,1.65]$ & & & & \\
\hline Takahashi et al. 2017 & 1.60740 .3588 & $8 \quad 16.9 \%$ & $4.99[2.47,10.08]$ & & & & \\
\hline Total $(95 \% \mathrm{Cl})$ & & $100.0 \%$ & $1.65[0.88,3.11]$ & & & & \\
\hline \multicolumn{8}{|c|}{ 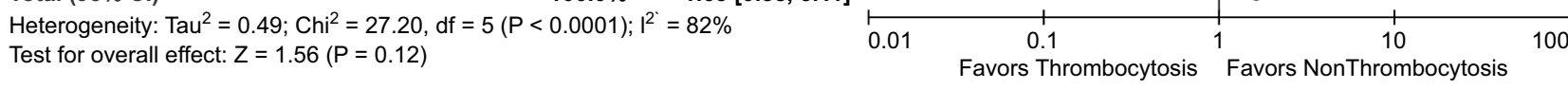 } \\
\hline
\end{tabular}

\begin{tabular}{|c|c|c|c|c|}
\hline Study or Subgroup & log[Hazard Ratio] & SE & Weight & $\begin{array}{c}\text { Hazard Ratio } \\
\text { IV, Random, } 95 \% \mathrm{Cl}\end{array}$ \\
\hline Abu-Zaid et al. 2017 & 0.8679 & 0.4495 & $20.6 \%$ & $2.38[0.99,5.75]$ \\
\hline Heng et al. 2014 & 0.7129 & 0.4776 & $19.3 \%$ & $2.04[0.80,5.20]$ \\
\hline Kizer et al. 2016 & 0.8065 & 0.2936 & $29.5 \%$ & $2.24[1.26,3.98]$ \\
\hline Moeini et al. 2016 & -0.1508 & 0.2767 & $30.6 \%$ & $0.86[0.50,1.48]$ \\
\hline Total $(95 \% \mathrm{Cl})$ & & & $100.0 \%$ & $1.66[0.96,2.89]$ \\
\hline \multicolumn{5}{|c|}{ Heterogeneity: $\mathrm{Tau}^{2}=0.18 ; \mathrm{Chi}^{2}=7.35, \mathrm{df}=3(P=0.06) ; \mathrm{I}^{2}=59 \%$} \\
\hline \multicolumn{5}{|c|}{ Test for overall effect: $Z=1.80(P=0.07)$} \\
\hline
\end{tabular}

Test for overall effect: $Z=1.80(P=0.07)$

Favors Thrombocytosis Favors NonThrombocytosis

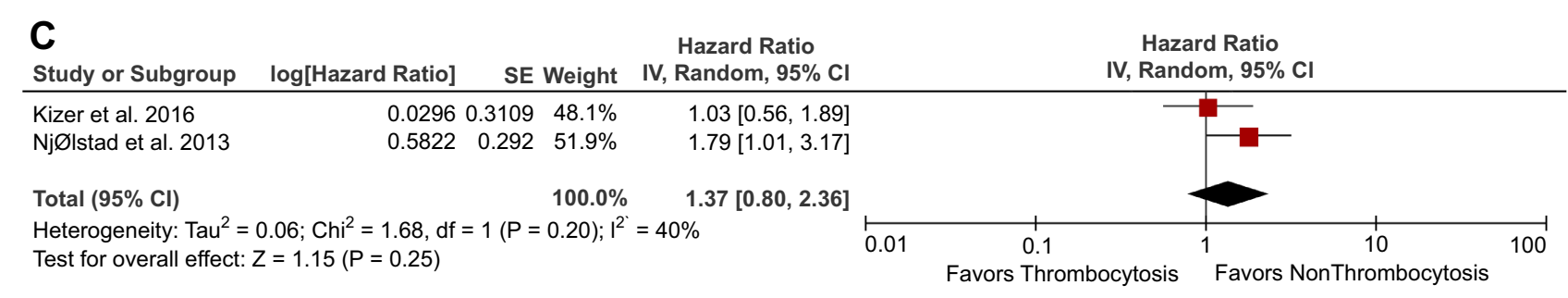

Figure 4 The association between thrombocytosis and survival outcomes (all multivariate analysis). (A) overall survival; (B) disease-free survival; and (C) cancer/diseasespecific survival.

Table 2 Subgroup analyses for OS and DFS

\begin{tabular}{|c|c|c|c|c|c|c|c|c|c|c|}
\hline \multirow[t]{2}{*}{ Subgroups } & \multirow[t]{2}{*}{$\mathbf{N}$} & \multicolumn{3}{|c|}{ Pooled OS } & \multirow[t]{2}{*}{$I^{2}$} & \multirow[t]{2}{*}{$\mathbf{N}$} & \multicolumn{3}{|c|}{ Pooled DFS } & \multirow[t]{2}{*}{$I^{2}$} \\
\hline & & HR & $95 \% \mathrm{Cl}$ & $P$-value & & & HR & $95 \% \mathrm{Cl}$ & $P$-value & \\
\hline \multicolumn{11}{|l|}{ Geographic region } \\
\hline Asian & 3 & 1.77 & $0.46-6.79$ & 0.41 & $91 \%$ & 2 & 2.21 & $1.17-4.21$ & 0.02 & $0 \%$ \\
\hline Non-Asian & 3 & 1.52 & $0.83-2.79$ & 0.17 & $58 \%$ & 2 & 1.38 & $0.54-3.53$ & 0.50 & $82 \%$ \\
\hline \multicolumn{11}{|l|}{ NOS score } \\
\hline$\leq 7$ & 4 & 1.90 & $0.94-3.81$ & 0.07 & $77 \%$ & 2 & 1.35 & $0.50-3.63$ & 0.56 & $73 \%$ \\
\hline$>7$ & 2 & 1.31 & $0.29-5.91$ & 0.73 & $85 \%$ & 2 & 2.18 & $1.34-3.56$ & 0.002 & $0 \%$ \\
\hline \multicolumn{11}{|l|}{ Sample size } \\
\hline Small $(\leq 200)$ & 3 & 1.88 & $1.26-2.80$ & 0.002 & $0 \%$ & I & 2.38 & $0.99-5.75$ & 0.05 & NA \\
\hline Large $(>200)$ & 3 & 1.39 & $0.44-4.45$ & 0.57 & $91 \%$ & 3 & 1.52 & $0.77-3.00$ & 0.22 & $68 \%$ \\
\hline
\end{tabular}

Abbreviations: DFS, disease-free survival; NOS, Newcastle-Ottawa Scale; OS, overall survival.

The prognosis remains dismal for patients with recurrent or metastatic EnCa. In order to improve survival, it is imperative that we identify the tumors with aggressive behaviors and treat them appropriately. Recently, studies have been reported that circulating biomarkers can predict the course of EnCa. Indices of systemic inflammation such as elevated platelet/lymphocyte ratio, platelet count and platelet volume have shown potential for prognostic 
Table 3 Sensitivity analysis for OS and DFS

\begin{tabular}{|c|c|c|c|c|}
\hline \multirow{2}{*}{$\begin{array}{l}\text { Outcomes } \\
\text { OS }\end{array}$} & \multirow[t]{2}{*}{ Study omitted } & \multicolumn{3}{|c|}{ Pooled results } \\
\hline & & HR & $95 \% \mathrm{Cl}$ & $P$-value \\
\hline & $\begin{array}{l}\text { Abu-Zaid et al } \\
2017 \\
{\text { Gorelick et } \text { al }^{16}}_{2009} \\
\text { Heng } \\
\text { and Benjapibal } \\
2014 \\
\text { Lerner et al }^{19} 2007 \\
\text { Moeini et al }{ }^{20} 2016 \\
\text { Takahashi et al } \\
2017\end{array}$ & $\begin{array}{l} \\
1.50 \\
1.90 \\
1.27\end{array}$ & $\begin{array}{l}0.73-3.79 \\
1.11-3.73 \\
0.75-3.00 \\
0.89-4.04 \\
0.75-2.16\end{array}$ & $\begin{array}{l}0.25 \\
0.10 \\
0.37\end{array}$ \\
\hline DFS & $\begin{array}{l}\text { Abu-Zaid et al }{ }^{13} \\
2017 \\
\text { Heng } \\
\text { and Benjapibal }{ }^{10} \\
2014 \\
\text { Kizer et al }{ }^{17} 2015 \\
\text { Moeini et al }{ }^{20} 2016\end{array}$ & $\begin{array}{l}1.49 \\
2.23\end{array}$ & $\begin{array}{l}0.77-3.00 \\
0.79-3.22\end{array}$ & $\begin{array}{l}0.22 \\
0.19\end{array}$ \\
\hline
\end{tabular}

Abbreviations: DFS, disease-free survival; OS, overall survival.

surveillance. ${ }^{23,24}$ In addition, such circulating markers are readily monitored by relatively noninvasive means. Therefore, it is of great clinical significance to identify new circulating markers, combining with the established clinicopathologic prognostic factors, to improve the outcomes of patients with EnCa.

The mechanisms by which preoperative thrombocytosis correlates clinicopathological features of $\mathrm{EnCa}$ patients remains to be not fully elucidated. Several studies which put forward to plausible hypotheses may explain the correlations. Platelets can infiltrate into tumor tissue and contribute to tumor growth by secreting pro-angiogenic and protumorigenic factors including vascular endothelial growth factor, insulin-like growth factor 1 and $2 .{ }^{25}$ Platelet-tumor cell adhesion established a pro-metastatic microenvironment that protects cancer cells from immune surveillance. ${ }^{26}$ Orellana et $\mathrm{al}^{27}$ found that platelets acted as chemo-attractants to facilitate cancer cells migration through co-cultivating cancer cells with human platelets. The authors concluded that platelet-cancer interactions contributed to the cancer metastasis. On the one hand, a variety of tumor-related cytokines stimulates thrombopoiesis in cancer. Among them are IL-1, IL-6, and thrombopoietin (TPO). ${ }^{28}$ Stone et al ${ }^{29}$ established mouse models of ovarian cancer and demonstrated that tumor-derived IL-6 stimulates hepatic production of TPO, which stimulates megakaryocyte growth and thrombopoiesis. In addition, Inhibition of IL- 6 by neutralizing antibody reduced tumor growth and enhanced the therapeutic efficacy of paclitaxel. Recently, Guillem-Llobat et $\mathrm{al}^{30}$ reported that low-dose aspirin which inhibits platelet activation prevented colorectal cancer metastasis in mice. Other antiplatelet agents such as heparinoids may be beneficial for cancer patients.

\section{Limitations}

Certain limitations exist in the current study. First, the cutoff point of preoperative thrombocytosis is still not established. Most of the included studies set cutoff point as platelet count $>400 \times 10^{9} / \mathrm{L}$, but Njølstad et $\mathrm{al}^{18}$ report thrombocytosis as platelet count $>390 \times 10^{9}$ platelets $/ \mathrm{L}$, which may lead to inter-study heterogeneity. Besides, the majority of included studies were retrospective, so the possibility of selection bias cannot be ruled out. Second, several disease conditions such as inflammatory hematological diseases may affect platelet count, but some included studies did not control these confounding factors. Third, the sample size of the included studies ranged from 68 to 714 , which may result in between-study heterogeneity. The limited number of included studies might impact the validity of our analysis, so further studies are warranted. These limitations may also contribute to the conflicting results of the prognostic significance of thrombocytosis in EnCa. Besides, a study by Oge $\mathrm{T}$ et $\mathrm{al}^{24}$ reported that platelet volume can be used as a parameter for platelet activation and prediction of advanced-stage EnCa. All included studies highlighted on platelet count, rather than function. Thus, the association of platelet volume with the survival of EnCa deserves further investigation.

\section{Conclusion}

In summary, the current meta-analysis shows that preoperative thrombocytosis is correlated with high FIGO stage, poor tumor differentiation, LVSI, myometrial invasion, cervical involvement, and lymph node metastasis. No significance was found between thrombocytosis and OS, DFS, and DSS. However, further studies are needed to update our results.

\section{Disclosure}

The authors report no conflicts of interest in this work. 


\section{References}

1. Morice P, Leary A, Creutzberg C, Abu-Rustum N, Darai E. Endometrial cancer. Lancet. 2016;387(10023):1094-1108. doi:10.1016/S0140-6736(15)00130-0

2. Siegel RL, Miller KD, Jemal A. Cancer statistics, 2017. CA Cancer J Clin. 2017;67(1):7-30. doi:10.3322/caac.21387

3. Pectasides D, Pectasides E, Economopoulos T. Systemic therapy in metastatic or recurrent endometrial cancer. Cancer Treat Rev. 2007;33(2):177-190. doi:10.1016/j.ctrv.2006.10.007

4. Gupta D. Clinical behavior and treatment of endometrial cancer. $A d v$ Exp Med Biol. 2017;943:47-74. doi:10.1007/978-3-319-43139-0_2

5. Murali R, Soslow RA, Weigelt B, et al. Classification of endometrial carcinoma: more than two types. Lancet Oncol. 2014;15(7):e268-78. doi:10.1016/S1470-2045(13)70591-6

6. Todenhöfer T, Renninger M, Schwentner C, Stenzl A, Gakis G. A new prognostic model for cancer-specific survival after radical cystectomy including pretreatment thrombocytosis and standard pathological risk factors. BJU Int. 2012;110(11Pt B):E533-40. doi:10.1111/bju.2012.110.issue-11b

7. Cohen JG, Tran AQ, Rimel BJ, et al. Thrombocytosis at secondary cytoreduction for recurrent ovarian cancer predicts suboptimal resection and poor survival. Gynecol Oncol. 2014;132(3):556-559. doi:10.1016/j.ygyno.2014.01.003

8. Koulis TA, Kornaga EN, Banerjee R, et al. Anemia, leukocytosis and thrombocytosis as prognostic factors in patients with cervical cancer treated with radical chemoradiotherapy: A retrospective cohort study. Clin Transl Radiat Oncol. 2017;4:51-56. doi:10.1016/j. ctro.2017.05.001

9. Takahashi R, Mabuchi S, Kuroda H, et al. The significance of pretreatment thrombocytosis and its association with neutrophilia in patients with surgically treated endometrial cancer. Int $J$ Gynecol Cancer. 2017;27(7):1399-1407. doi:10.1097/IGC.0000000000001019

10. Heng S, Benjapibal M. Preoperative thrombocytosis and poor prognostic factors in endometrial cancer. Asian Pac J Cancer Prev. 2014;15(23):10231-10236.

11. Liberati A, Altman DG, Tetzlaff J, et al. The PRISMA statement for reporting systematic reviews and meta-analyses of studies that evaluate health care interventions: explanation and elaboration. PLoS Med. 2009;6(7):e1000100. doi:10.1371/journal.pmed.1000100

12. Stang A. Critical evaluation of the Newcastle-Ottawa scale for the assessment of the quality of nonrandomized studies in meta-analyses. Eur J Epidemiol. 2010;25(9):603-605. doi:10.1007/s10654-010-9491-z

13. Abu-Zaid A, Alsabban M, Abuzaid M, AlOmar O, Salem H, AlBadawi IA. Preoperative thrombocytosis as a prognostic factor in endometrioid-type endometrial carcinoma. Ann Saudi Med. 2017;37 (5):393-400. doi:10.5144/0256-4947.2017.393

14. Andersen CL, Eskelund CW, Siersma VD, et al. Is thrombocytosis a valid indicator of advanced stage and high mortality of gynecological cancer? Gynecol Oncol. 2015;139(2):312-318. doi:10.1016/j.ygyno.2015.09.017

15. Gücer F, Moser F, Tamussino K, et al. Thrombocytosis as a prognostic factor in endometrial carcinoma. Gynecol Oncol. 1998;70(2):210-214. doi:10.1006/gyno.1998.5078

16. Gorelick C, Andikyan V, Mack M, Lee YC, Abulafia O. Prognostic significance of preoperative thrombocytosis in patients with endometrial carcinoma in an inner-city population. Int $J$ Gynecol Cancer. 2009;19(8):1384-1389. doi:10.1111/IGC.0b013e3181a47d47
17. Kizer NT, Hatem H, Nugent EK, et al. Chemotherapy response rates among patients with endometrial cancer who have elevated serum platelets. Int J Gynecol Cancer. 2015;25(6):1015-1022. doi:10.1097/ IGC.0000000000000453

18. Njølstad TS, Engerud H, Werner HM, Salvesen HB, Trovik J. Preoperative anemia, leukocytosis and thrombocytosis identify aggressive endometrial carcinomas. Gynecol Oncol. 2013;131 (2):410-415. doi:10.1016/j.ygyno.2013.08.032

19. Lerner DL, Walsh CS, Cass I, Karlan BY, Li AJ. The prognostic significance of thrombocytosis in uterine papillary serous carcinomas. Gynecol Oncol. 2007;104(1):91-94. doi:10.1016/j.ygyno.2006. 07.020

20. Moeini A, Machida H, Takiuchi T, et al. Association of nonalcoholic fatty liver disease and venous thromboembolism in women with endometrial cancer. Clin Appl Thromb Hemost. 2016;23 (8):1018-1027. doi:10.1177/1076029616665925

21. Wang YH, Deng SJ, Yang YD, et al. The pretreatment thrombocytosis may predict prognosis of patients with colorectal cancer: a systematic review and meta-analysis. Biomark Med. 2017;11 (2):195-210. doi:10.2217/bmm-2016-0214

22. Wang YH, Kang JK, Zhi YF, et al. The pretreatment thrombocytosis as one of prognostic factors for gastric cancer: A systematic review and meta-analysis. Int $J$ Surg. 2018;53:304-311. doi:10.1016/j. ijsu.2018.03.084

23. Cummings M, Merone L, Keeble C, et al. Preoperative neutrophil: lymphocyteand platelet: lymphocyteratios predict endometrial cancer survival. $\quad B r \quad J$ Cancer. 2015;113(2):311-320. doi:10.1038/ bjc. 2015.200

24. Oge T, Yalcin OT, Ozalp SS, Isikci T. Platelet volume as a parameter for platelet activation in patients with endometrial cancer. $J$ Obstetrics Gynaecol. 2013;33(3):301-304. doi:10.3109/ 01443615.2012.758089

25. Wojtukiewicz MZ, Sierko E, Hempel D, Tucker SC, Honn KV. Platelets and cancer angiogenesis nexus. Cancer Metastasis Rev. 2017;36(2):249-262. doi:10.1007/s10555-017-9673-1

26. Li N. Platelets in cancer metastasis: to help the "villain" to do evil. Int $J$ Cancer. 2016;138(9):2078-2087. doi:10.1002/ ijc. 29847

27. Orellana R, Kato S, Erices R, et al. Platelets enhance tissue factor protein and metastasis initiating cell markers, and act as chemoattractants increasing the migration of ovarian cancer cells. BMC Cancer. 2015;15:290. doi:10.1186/s12885-015-1584-3

28. Menter DG, Tucker SC, Kopetz S, Sood AK, Crissman JD, Honn KV. Platelets and cancer: a casual or causal relationship: revisited. Cancer Metastasis Rev. 2014;33(1):231-269. doi:10.1007/s10555-014-9498-0

29. Stone RL, Nick AM, McNeish IA, et al. Paraneoplastic thrombocytosis in ovarian cancer. $N$ Engl $J$ Med. 2012;366(7):610-618. doi:10.1056/NEJMoa1110352

30. Guillem-Llobat P, Dovizio M, Bruno A, et al. Aspirin prevents colorectal cancer metastasis in mice by splitting the crosstalk between platelets and tumor cells. Oncotarget. 2016;7(22):32462-32477. doi:10.18632/oncotarget.8655

31. Wells GA, Shea B, O'Connell D, et al. The Newcastle-Ottawa Scale (NOS) for assessing the quality of nonrandomized studies in metaanalyses. Ottawa Hospital Research Institute. Available from: http:// www.ohri.ca/programs/clinical_epidemiology/oxford.asp. Accessed July 10, 2018. 


\section{Supplementary materials}

Table SI Newcastle-Ottawa quality assessment scale

\section{Selection}

(I) Representativeness of the exposed cohort

(a) Truly representative of the average "endometrial cancer patient" in the community (I star)

(b) Somewhat representative of the average 'endometrial cancer patient in the community (I star)

(c) Selected group of users (eg, nurses, volunteers)

(d) No description of the derivation of the cohort

(2) Selection of the non-exposed cohort

(a) Drawn from the same community as the exposed cohort (I star)

(b) Drawn from a different source

(c) No description of the derivation of the non-exposed cohort

(3) Ascertainment of exposure

(a) Secure record (eg, surgical records) (I star)

(b) Structured interview (I star)

(c) Written self-report

(d) No description

(4) Demonstration that outcome of interest was not present at start of study

(a) Yes (I star)

(b) No

\section{Comparability}

(I) Comparability of cohorts on the basis of the design or analysis

(a) Study controls for confounder factor (factors that may affect hematologic parameters) (I star)

(b) Study controls for any additional factor (I star) (age, gender, stage, etc.)

\section{Outcome}

(I) Assessment of outcome (death or recurrence or progression)
(a) Independent blind assessment (I star)
(b) Record linkage (I star)
(c) Self-report
(d) No description

(2) Was follow-up long enough for outcomes to occur?
(a) Yes (I star)
(b) No

(3) Adequacy of follow-up of cohorts

(a) Complete follow-up - all subjects accounted for (I star)

(b) Subjects lost to follow-up unlikely to introduce bias - small number lost "(25\%)" or description provided of those lost (I star)

(c) Follow-up rate less than "75\%" and no description of those lost

(d) No statement

Notes: Reproduced with permission from Wells GA, Shea B, O'Connell D, et al. The Newcastle-Ottawa Scale (NOS) for assessing the quality of nonrandomized studies in metaanalyses. Ottawa Hospital Research Institute. Available from: http://www.ohri.ca/programs/clinical_epidemiology/oxford.asp.' 


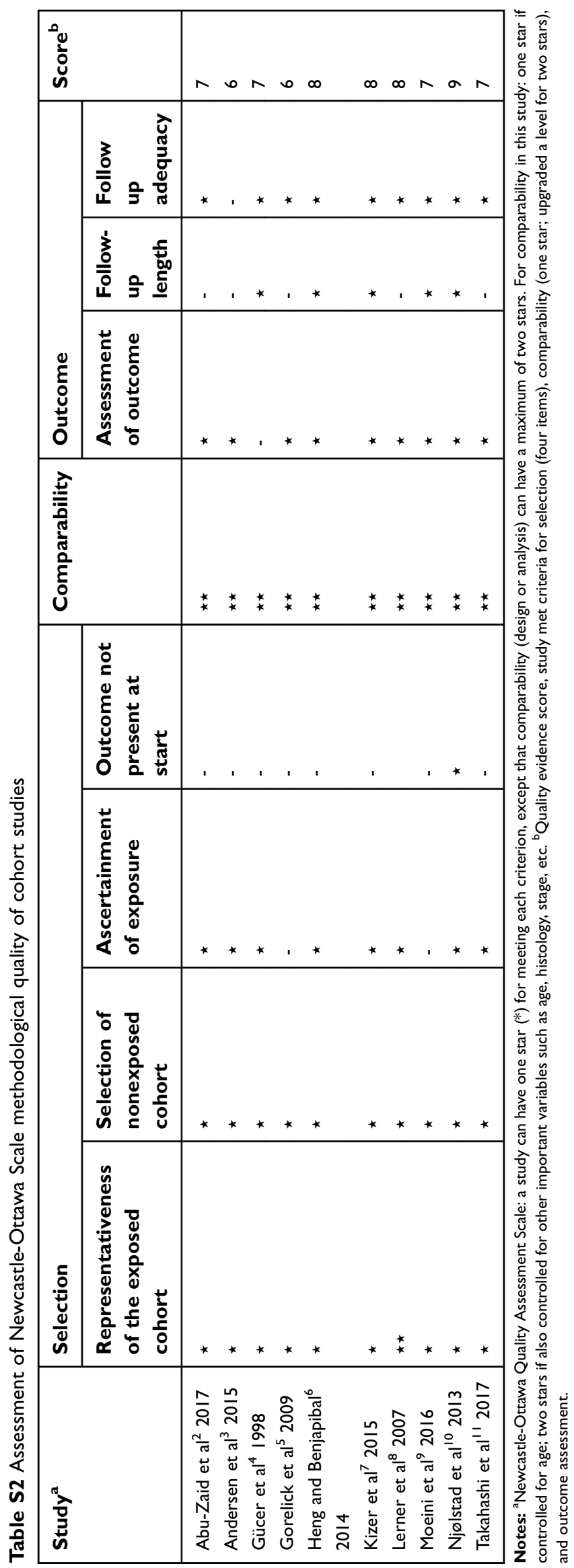




\section{Search strategy \\ PubMed:}

\#1: Search $\quad((()(()(()(()(()(($ Endometrial Neoplasm[Title) Abstract]) OR Neoplasm, Endometrial[Title/Abstract]) OR Neoplasms, Endometrial[Title/Abstract]) OR Endometrial Carcinoma[Title/Abstract]) OR Carcinoma, Endometrial [Title/Abstract]) OR Carcinomas, Endometrial[Title/ Abstract]) OR Endometrial Carcinomas[Title/Abstract]) OR Endometrial cancer[Title/Abstract]) OR Cancer, Endometrial [Title/Abstract]) OR Cancers, Endometrial[Title/Abstract]) OR Endometrial Cancers[Title/Abstract]) OR Endometrium Cancer[Title/Abstract]) OR Cancer, Endometrium[Title/ Abstract]) OR Cancers, Endometrium[Title/Abstract]) OR Cancer of the Endometrium[Title/Abstract]) OR Carcinoma of Endometrium[Title/Abstract]) OR Endometrium Carci noma[Title/Abstract]) OR Endometrium Carcinomas[Title/ Abstract]) OR Cancer of Endometrium[Title/Abstract]) 38,079

\#2: Search ((()(((Thrombocytosis[Title/Abstract]) OR Thrombocytoses[Title/Abstract]) OR Thrombocythemia [Title/Abstract]) OR Thrombocythemias[Title/Abstract]) OR Increased platelets[Title/Abstract]) OR Increased platelet[Title/Abstract]) OR platelets count[Title/Abstract]) OR platelet count[Title/Abstract] 29,942

\#3: Search $((()((()((()(((“ P r o g n o s i s ”[M e s h]))$ OR Prognosis [Title/Abstract]) OR Prognoses[Title/Abstract]) OR Prognostic[Title/Abstract]) OR Outcome[Title/Abstract]) OR Survival[Title/Abstract]) OR Overall survival[Title/ Abstract]) OR OS[Title/Abstract]) OR Cancer-specific survival[Title/Abstract]) OR CSS[Title/Abstract]) OR Progression-free survival[Title/Abstract]) OR PFS[Title/ Abstract]) OR Disease-free survival[Title/Abstract]) OR DFS[Title/Abstract]) OR Mortality[Title/Abstract]) OR Recurrence[Title/Abstract] 3,215,415

\#4: \#1 and \#2 and \#3 38

\section{Embase:}

("thrombocytosis":ab,ti OR "thrombocytoses":ab,ti OR "thrombocythemia":ab,ti OR "thrombocythemias":ab,ti OR “increased platelets”:ab,ti OR “increased platelet”:ab, ti OR “platelets count":ab,ti OR “platelet count":ab,ti) AND [1966-2018]/py 49,707

"prognosis"/exp/mj OR prognosis:ab,ti OR prognoses:ab,ti OR prognostic:ab,ti OR outcome:ab,ti OR survival:ab,ti OR "overall survival":ab,ti OR os OR “cancer-specific survival": ab,ti OR css:ab,ti OR “progression-free survival”:ab,ti OR pfs:ab,ti OR “disease-free survival”:ab,ti OR dfs:ab,ti OR mortality:ab,ti OR recurrence:ab,ti 3,462,505

(“endometrial cancer":ab,ti OR “endometrial neoplasm”:ab, ti OR “neoplasm, endometrial”:ab,ti OR “neoplasms, endometrial":ab,ti OR "endometrial carcinoma":ab,ti OR “carcinoma, endometrial":ab,ti OR “carcinomas, endometrial":ab, ti OR "endometrial carcinomas":ab,ti OR “cancer, endometrial":ab,ti OR “cancers, endometrial”:ab,ti OR “endometrial cancers":ab,ti OR “cancer, endometrium":ab,ti OR “cancers, endometrium":ab,ti OR “cancer of the endometrium":ab,ti OR “carcinoma of endometrium":ab,ti OR "endometrium carcinoma":ab,ti OR “endometrium carcinomas":ab,ti OR “cancer of endometrium":ab,ti) AND [1966-2018]/py 31,021

\#4: \#1 and \#2 and \#3 35

\section{Springerlink 178}

\section{ScienceDirect 88}

\section{References}

1. Wells GA, Shea B, O'Connell D, et al. The Newcastle-Ottawa Scale (NOS) for assessing the quality of nonrandomized studies in metaanalyses. Ottawa Hospital Research Institute. Available from: http:// www.ohri.ca/programs/clinical_epidemiology/oxford.asp. Accessed July 10, 2018.

2. Abu-Zaid A, Alsabban M, Abuzaid M, AlOmar O, Salem H, AlBadawi IA. Preoperative thrombocytosis as a prognostic factor in endometrioid-type endometrial carcinoma. Ann Saudi Med. 2017;37 (5):393-400. doi:10.5144/0256-4947.2017.393

3. Andersen CL, Eskelund CW, Siersma VD, et al. Is thrombocytosis a valid indicator of advanced stage and high mortality of gynecological cancer? Gynecol Oncol. 2015;139(2):312-318. doi:10.1016/j. ygyno.2015.09.017.

4. Gücer F, Moser F, Tamussino K, et al. Thrombocytosis as a prognostic factor in endometrial carcinoma. Gynecol Oncol. 345 1998;70(2):210214. doi:10.1006/gyno.1998.5078

5. Gorelick C, Andikyan V, Mack M, Lee YC, Abulafia O. Prognostic significance of preoperative thrombocytosis in patients with endometrial carcinoma in an inner-city population. Int $J$ Gynecol Cancer. 2009;19(8):1384-1389. doi:10.1111/IGC.0b013e3181a47d47

6. Heng S, Benjapibal M. Preoperative thrombocytosis and poor prognostic factors in endometrial cancer. Asian Pac J Cancer Prev. 2014;15 (23):10231-10236

7. Kizer NT, Hatem H, Nugent EK, et al. Chemotherapy response rates among patients with endometrial cancer who have elevated serum platelets. Int J Gynecol Cancer. 2015;25(6):1015-1022. doi:10.1097/ IGC. 0000000000000453

8. Lerner DL, Walsh CS, Cass I, Karlan BY, Li AJ. The prognostic significance of thrombocytosis in uterine papillary serous carcinomas. Gynecol Oncol. 2007;104(1):91-94. doi:10.1016/j.ygyno.2006. 07.020

9. Moeini A, Machida H, Takiuchi T, et al. Association of nonalcoholic fatty liver disease and venous thromboembolism in women with endometrial cancer. Clin Appl Thromb Hemost. 2016;23(8):1018-1027. doi:10.1177/107602961666592510. 
10. Njølstad TS, Engerud H, Werner HM, Salvesen HB, Trovik J. 355 Preoperative anemia, leukocytosis and thrombocytosis identify aggressive endometrial carcinomas. Gynecol Oncol. 2013;131 (2):410-415. doi:10.1016/j.ygyno.2013.08.032
11. Takahashi R, Mabuchi S, Kuroda H, et al. The significance of pretreatment thrombocytosis and its association with neutrophilia in patients with surgically treated endometrial cancer. Int J Gynecol Cancer. 2017;27(7):1399-1407. doi:10.1097/IGC.0000000000001019

\section{Publish your work in this journal}

Cancer Management and Research is an international, peer-reviewed open access journal focusing on cancer research and the optimal use of preventative and integrated treatment interventions to achieve improved outcomes, enhanced survival and quality of life for the cancer patient
The manuscript management system is completely online and includes a very quick and fair peer-review system, which is all easy to use. Visit http://www.dovepress.com/testimonials.php to read real quotes from published authors. 